\title{
Use of soluble swabs in the diagnosis of bladder neoplasia
}

\author{
P. A. TROTT, GRANT Williams, AND P. W. ATtRidge
}

From the Department of Pathology, Imperial Cancer Research Fund, London, and the Institute of Urology, London

SYNOPSIS A technique is described for obtaining samples of bladder epithelium using soluble swabs. Changes indicating neoplasia were seen in a large proportion of patients with bladder carcinoma. These changes were absent in the non-neoplastic control cases. The method provided tissue similar to that obtained by biopsy and surgical removal. The cellular appearances resembled those seen in neoplastic cells exfoliated into urine.

Soluble swabs of cellulose acetate were first used by Kuper, Stradling, Davis, and Shortridge (1966) for obtaining samples of respiratory tract epithelium at bronchoscopy. We have used this technique for removing tissue from bladder epithelium and this paper reports our findings in a series of 67 patients. Some of the clinical results have already been described (Williams, 1968).

\section{MATERIALS AND METHODS}

The synthetic fibre used for making the swabs is obtainable from British Celanese Limited. It is marketed Received for publication 13 May 1969. under the name of Celafibre (15 denier, 3 in. bright, untinted) and has the appearance and consistency of cotton wool. For our purpose wisps of the material were compressed by hand into swabs approximately $0.75 \mathrm{~cm}$ in diameter. Ether effectively removed the grease caused by rolling the material between the fingers and it was convenient to keep the swabs in a bottle of this solvent.

The dry autoclaved swab was held tightly by a wire snare in the tip of a ureteric catheter. This was inserted through a Graham or a Riches cystoscope, the former having two advantages. First a wider field of vision was obtained (Fig. 1), and secondly the catheter was held securely in the ring through which it passed. In the Riches cystoscope the Albarran lever did not support the catheter sufficiently and it easily became displaced

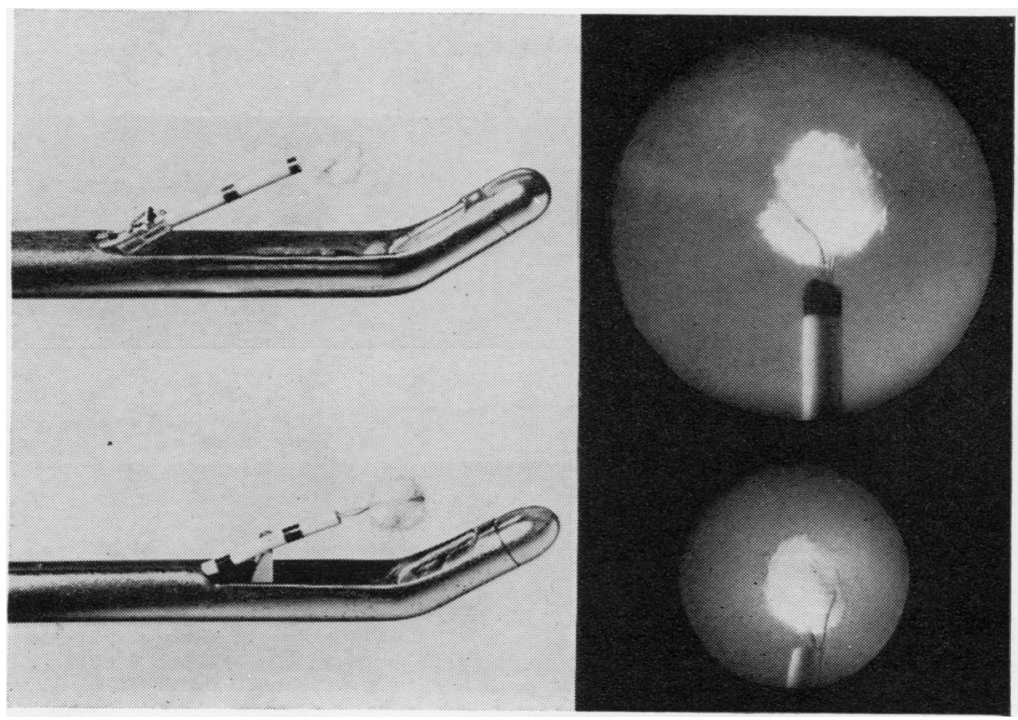

FIG. 1. Soluble swab fixed by $a$ wire snare to $a$ ureteric catheter in a Graham cystoscope (top) and Riches cystoscope (bottom). Right, simulated view of swabs in position. 
from the field of view. Specimens were obtained by rotating the instrument slightly and raising and lowering the catheter tip, thereby applying the swab to the surface of the lesion. Adequate specimens could also be obtained by holding the swab in flexible biopsy forceps but this procedure was more difficult to control than the wire snare method. Contamination by urethral epithelial cells was prevented by removing the swab before the sheath of the cystoscope.

The swab was immediately fixed in formol sublimate for one to two hours. This gave the best nuclear staining provided the swab was removed from fixative within four to six hours; $10 \%$ neutral buffered formalin was convenient if specimens were liable to be delayed in transit. The swab was transferred from the fixative, using non-toothed forceps, into a conical centrifuge tube containing $10 \mathrm{ml}$ acetone. Gentle shaking helped it to dissolve in a few seconds. The tube was centrifuged at $3,000 \mathrm{rpm}$ for three minutes and the supernatant discarded. The remaining cell deposit was moistened with a few drops of alcohol and was pipetted into a small hollow cone of polyvinyl chloride coated internally with $1 \%$ celloidin. The cone containing the cell deposit was centrifuged at 2,000 rpm for 10 minutes, the supernatant was removed and the top of the cone sealed with $1 \%$ celloidin.

The cone and its contents were processed as a piece of tissue through graded alcohols to chloroform which dissolved the cone leaving the cell button in its celloidin envelope. This was cleared in fresh chloroform, embedded in paraffin wax, and sections at various levels were stained with haematoxylin and eosin.

Since this paper was written the polyvinyl chloride cones have become unobtainable. Instead gelatin capsules, size 00 (Parke, Davis and Company), have been used successfully in a number of cases. Two per cent celloidin was used for coating the capsule internally and for sealing the deposit. After dehydration and clearing in xylene the capsule was gently cut away with a scalpel blade and the cell button and celloidin envelope were embedded.

The 67 patients were divided into three groups. The first of these provided the control series and consisted of 18 patients, none of whom had neoplastic disease of the urothelium or adjacent organs. The second group of 36 patients had tumours of the bladder epithelium. In group 3 there were 13 cases with a history of bladder tumour either with clinical findings suspicious of a recurrence or with a urinary infection.

\section{RESULTS}

GROUP 1: NON-NEOPLASTIC CONTROL CASES The ages of these patients ranged from 3 to 86 and half of them were aged 9 years or less. Most of the children had inflammatory conditions associated with congenital abnormalities of the bladder. Three adult males had benign enlargement of the prostate, four adults had cystitis, one man had an epididymoorchitis with haematuria, and one woman had postobstetric stress incontinence.

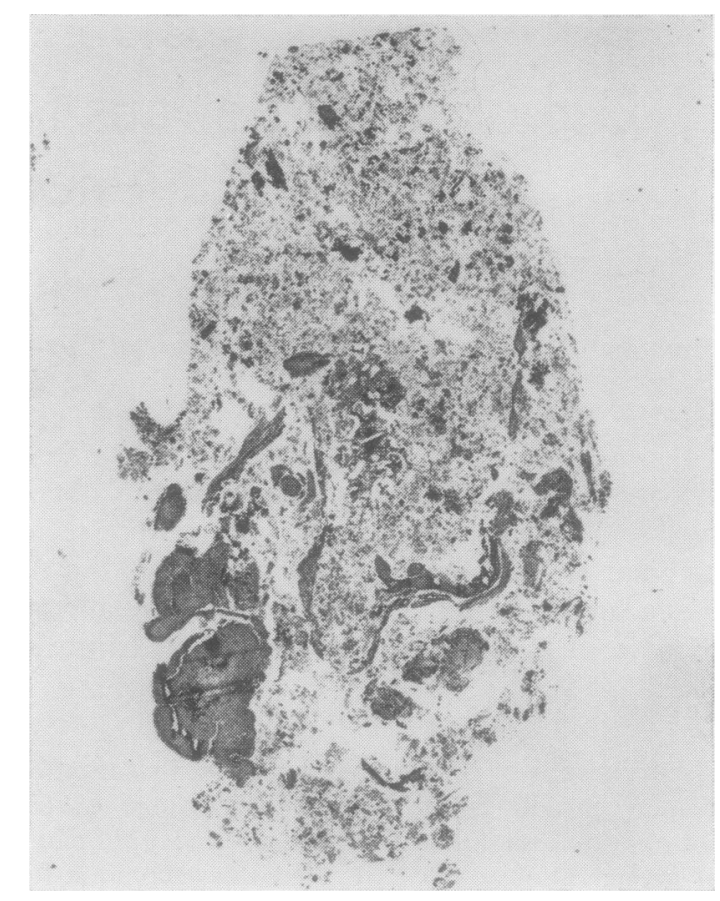

FIG. 2. Bladder swab section. Benign hypertrophy of prostate. Haematoxylin and eosin. $\times 15$.

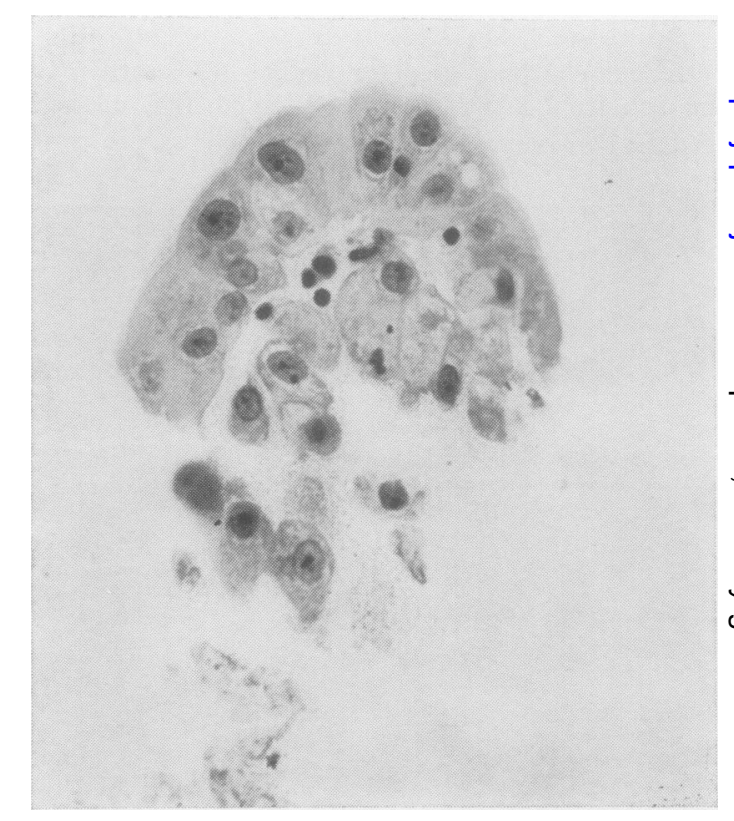
FIG. 3. Epithelial cells from bladder swab. Haematoxylin
and eosin. $\times 400$. 
The cellulose acetate dissolved completely from most of the swabs during processing but in a few instances its outline could still be seen. Occasionally a few small crystals and debris were present. The average amount of tissue removed by this technique is shown in Figure 2. Four cases, however, produced considerably fewer cells. Many of the patients with inflammatory conditions of the bladder showed aggregates of polymorphonuclear leucocytes mingled with epithelial cells. The specimen from one such case also contained clumps of bacteria.

The microscopic appearances of the epithelial cells were variable. Both individual cells and rows or groups of cells were present and sometimes epithelium with underlying stroma could be identified. Transitional cells with round or oval nuclei were seen and also columnar-shaped cells in a palisade arrangement. The cytoplasm was often brightly eosinophilic but sometimes it was faintly stained and had a lattice appearance. The nuclear chromatin of the larger cells was finely reticulated and often contained one nucleolus.

In sections of swabs from patients with a history of cystitis the nuclei tended to be large and often measured up to $14 \mu$ in diameter. Several measuring $10 \mu$ were pyknotic. Nucleoli were prominent and sometimes duplicated and a few mitotic figures were found in three cases. In the swabs from children these appearances were frequently seen. Figure 3 shows a clump of cells from a patient in whom a recent biopsy had shown chronic inflammation and no evidence of neoplasia. There was heavy pyuria and $E$. coli grew on culture.

GROUP 2: NEOPLASTIC CASES The results of the use of the soluble swab technique are shown in Table I. The ages of the patients ranged from 46 to 88 and 10 of them were women. Thirty-five of the tumours were primary neoplasms and one was a secondary carcinoma from the cervix uteri.

\section{TABLE I}

RESULTS OF THE SOLUBLE SWAB TECHNIQUE IN 36 NEOPLASTIC CASES OF GROUP 2

\begin{tabular}{lrll} 
Histology & \multicolumn{3}{c}{ Soluble Swab } \\
\cline { 3 - 4 } & & Positive & Negative \\
\hline Available & 33 & 30 & 3 \\
Not available & 3 & 2 & 1 \\
Total & 36 & 32 & 4
\end{tabular}

The majority of the tumours were papillary. Eight were described as nodular and one was an ulcerated area $4.5 \mathrm{~cm}$ in diameter. Twenty-six were more than $3 \mathrm{~cm}$ in diameter or were multifocal. Two measured approximately $1 \mathrm{~cm}$ and in one patient no lesion was seen on examination but was palpable bimanually. In seven cases the size of the tumour was not recorded.

The soluble swab sections showed fragments of tissue in many cases as well as small clusters and individual cells. The fragments sometimes included subepithelial stroma (Fig. 4) and the cellular pattern often appeared similar to that found in conventional histology (Figs. 5 and 6).

Tumour cells were present singly and in small groups. They were recognizable by their pleomorphic nuclear appearance which was similar to neoplastic cells exfoliated into the urine. Many had oval nuclei but some with elongated or more bizarre shapes were found. Although the nuclei varied in size, most were larger than normal. A consistent feature was a well defined nuclear border with an irregular edge. Following fixation in formol sublimate the nuclear chromatin appeared contracted, resulting in open spaces between clumps of chromatin. Usually numerous dyskaryotic cells were present in the swab section. In one case, however, a group of six atypical cells was the only abnormal finding (Fig. 7). The patient had a moderately differentiated transitional cell carcinoma and neoplastic cells of similar appearance were found in the urine deposit (Fig. 8).

Of the three negative swabs in which histology was available, two contained very few cells, none of which appeared abnormal. Although one of these tumours was approximately $1 \mathrm{~cm}$ in diameter the other measured $6 \mathrm{~cm}$ and it is likely that the surgeon failed to apply the swab to the surface of the lesion. These were the only two swabs in this group in which the procedure was unsatisfactory. The third swab was from a 61-year-old man in whom a biopsy 15 months previously had shown a transitional cell papilloma. The swab section showed numerous single transitional cells of normal size and others arranged in small clumps. As the growth was extensive and consisted of four separate lesions it is possible that these cells were derived from the neoplastic tissue.

Of the three patients from whom no histological confirmation of the tumour was available, two had changes in the swab sections suggesting carcinoma and one of these also exfoliated neoplastic cells into the urine. The swab from the third patient, who had a lesion approximately $1 \mathrm{~cm}$ in diameter, contained a moderate number of transitional cells of normal appearance.

In two cases tissue was obtained by swabbing the tumour in the freshly removed surgical specimen and appearances in the swab section and the orthodox histological section were found to be similar (Figs. 9 and 10). 


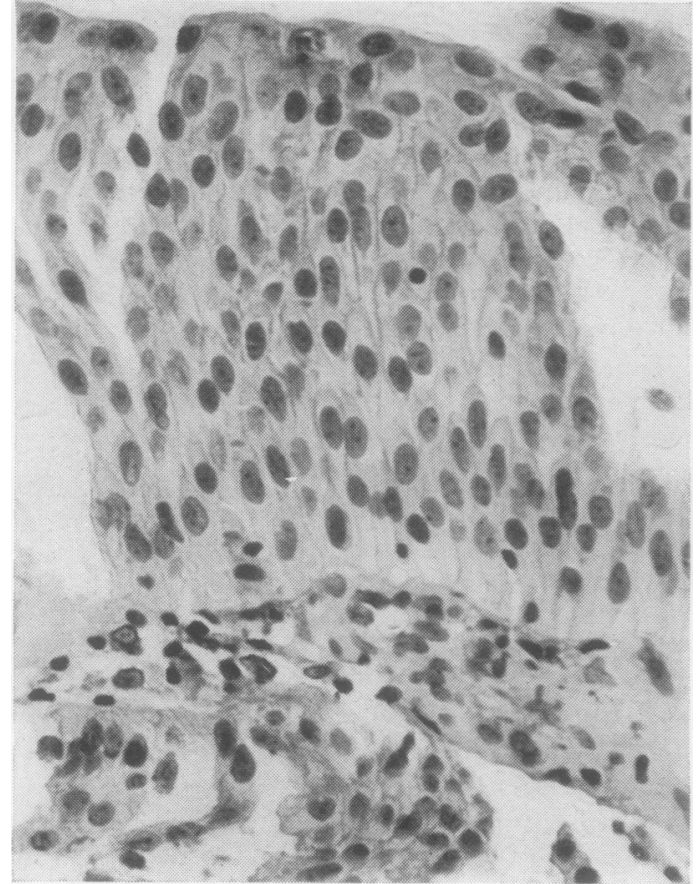

FIG. 4.

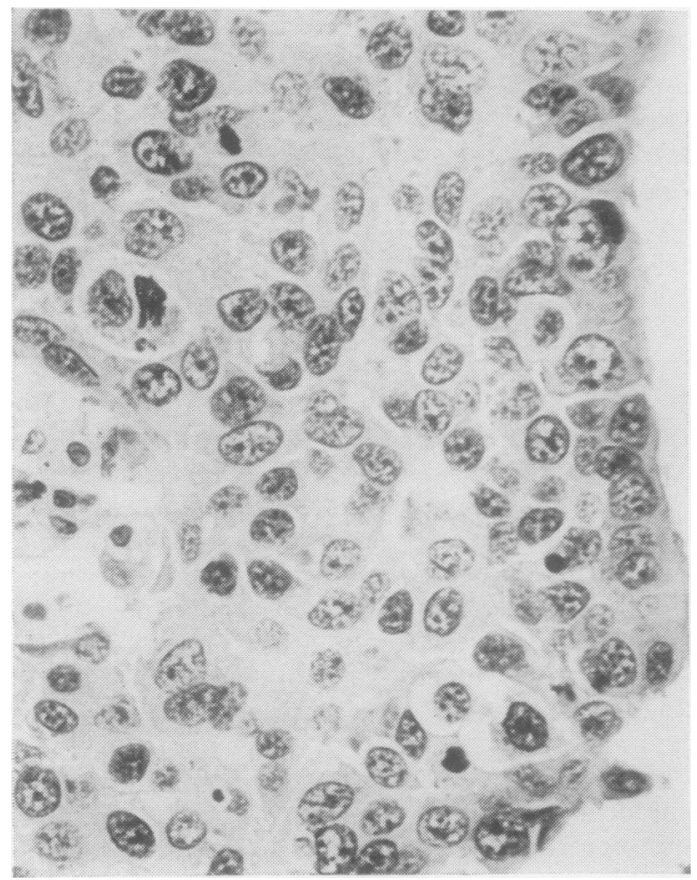

FIG. 6.

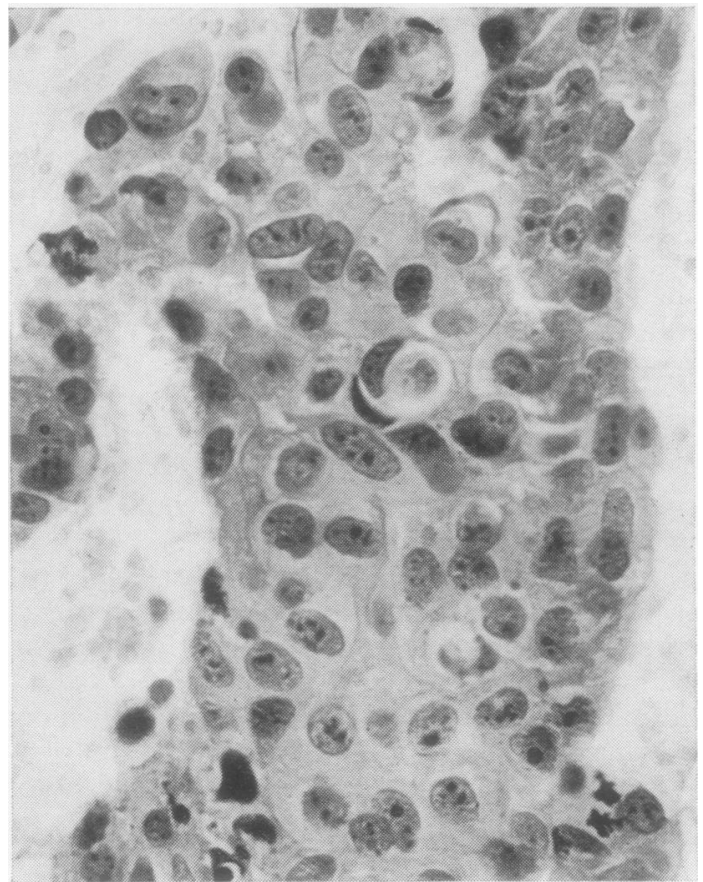

FIG. 5 .

FIG. 4. Bladder swab. Fragment of well differentiated transitional cell carcinoma with subepithelial stroma. Haematoxylin and eosin. $\times 400$.

FIG. 5. Clump of cells in soluble swab section from a nodular tumour. Haematoxylin and eosin. $\times 400$.

FIG. 6. Histology from biopsy showing anaplastic car- §ิ cinoma. Same case as in Figure 5. Haematoxylin and eosin. $\times 400$.

FIG. 7. Clump of atypical cells in bladder swab. Haematoxylin and eosin. $\times 400$.

FIG. 8. Cells in urinary deposit. Same case as in Figure 7. N Papanicolaou technique. $\times 400$.

FIG. 9. Swab section from ureteric tumour removed in fresh surgical specimen. Haematoxylin and eosin. $\times 400$. FIG. 10. Orthodox histological section. Same case as in
Figure 9. Haematoxylin and eosin. $\times 400$. FIG. 10. Orthodox histological section. Same case as in
Figure 9. Haematoxylin and eosin. $\times 400$. 


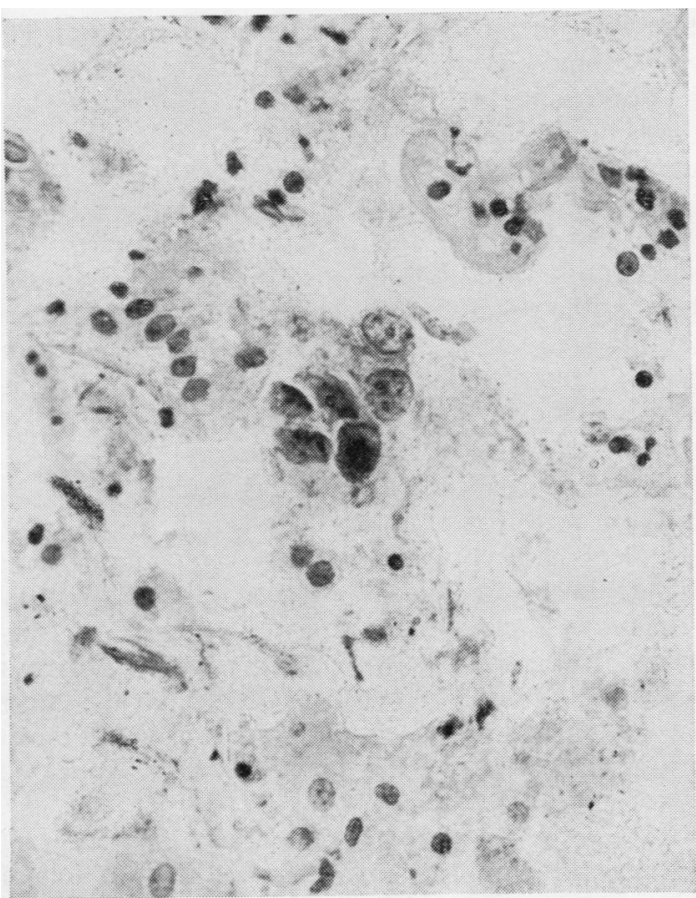

FIG. 7 .
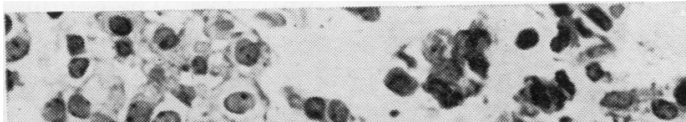

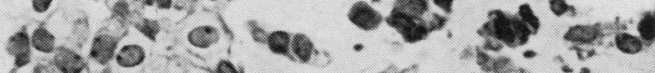

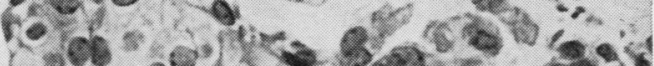

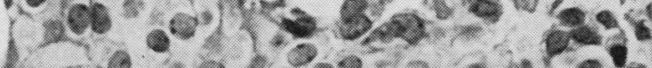

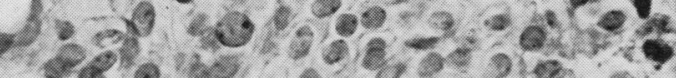

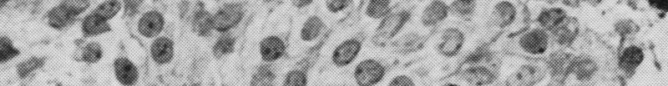

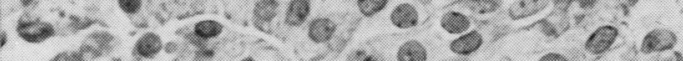

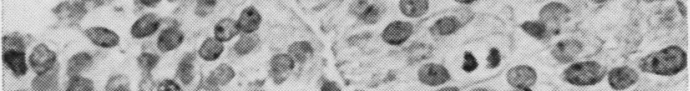

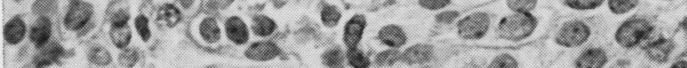

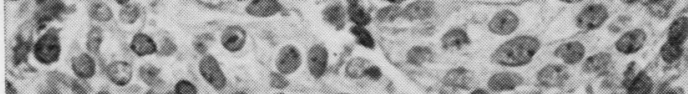

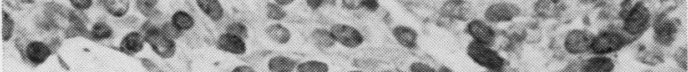
6.

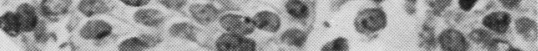

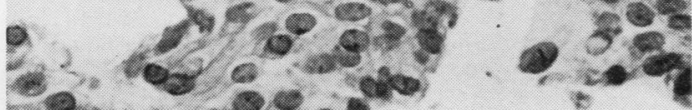

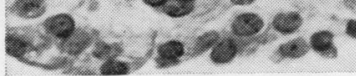

FIG. 9.

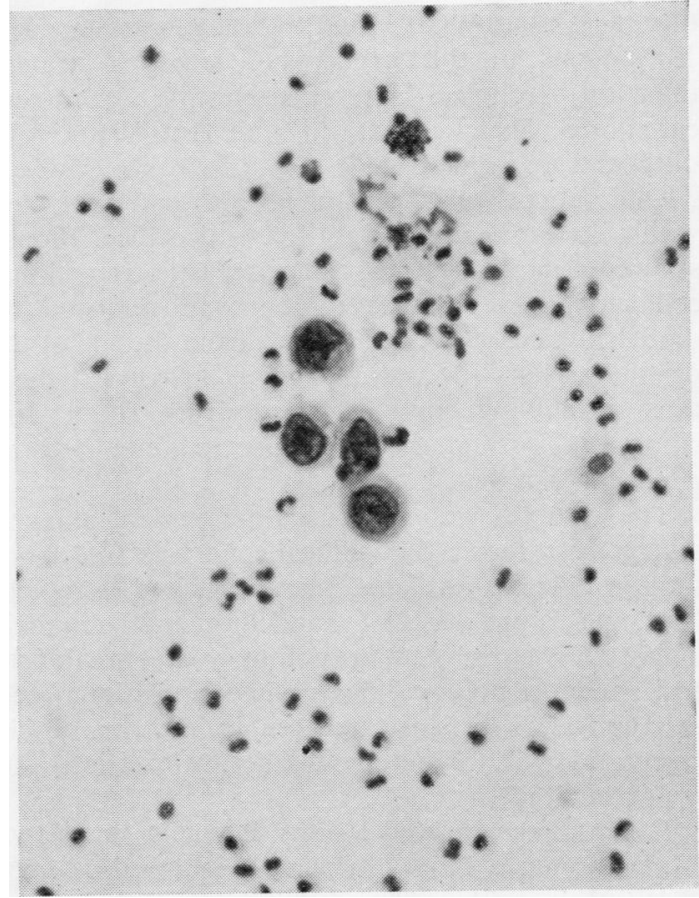

FIG- 8.

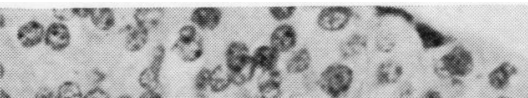

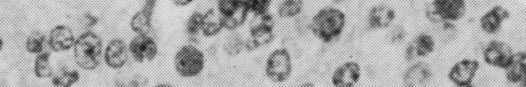

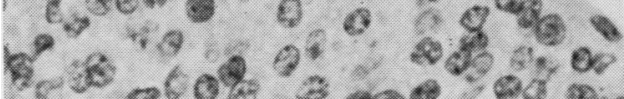

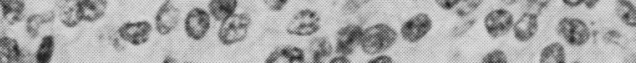

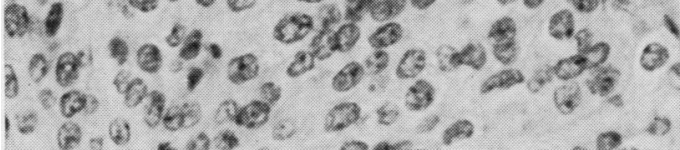

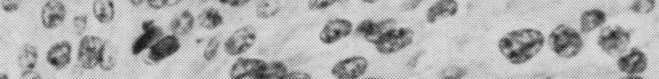

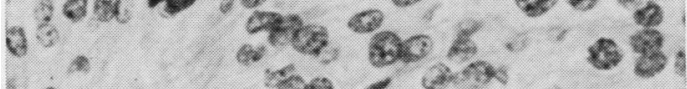

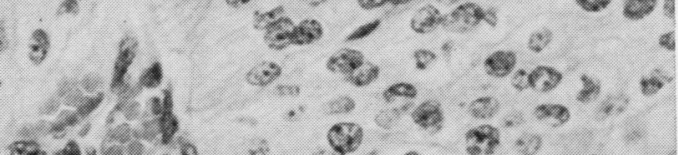

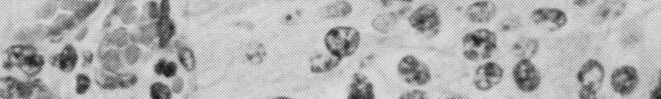

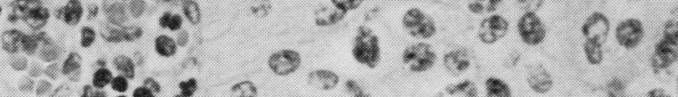

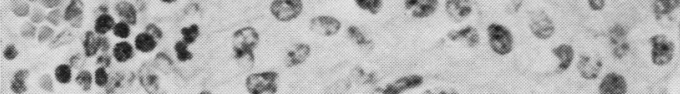

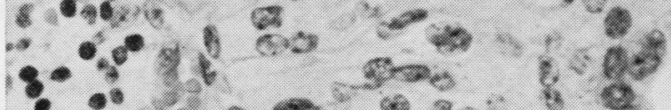

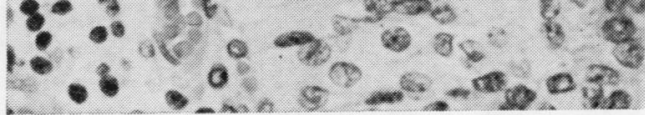

FIG. 10 . 
GROUP 3: CASES WITH A HISTORY OF NEOPLASIA The 13 patients in this group had either a urinary infection or clinical features suggesting a recurrent carcinoma. Their ages ranged from 41 to 80 and four of them were women.

One patient was a man of 63 who had presented with a lesion near the right ureteral orifice. Biopsy showed a papillary and solid anaplastic transitional cell carcinoma and the tumour was removed by diathermy. A soluble swab taken from the site of the original lesion showed numerous grossly atypical cells resembling some obtained from frank carcinomas. Ten months later a carcinoma became clinically apparent.

The soluble swab from another patient showed severe dyskaryosis but clinically he was free from tumour nine months later. Many cells had extremely large nuclei; one was $23.5 \mu$ and another $20 \mu$ in their widest diameters. A biopsy four years previously had shown a poorly differentiated transitional cell carcinoma which penetrated deeply into the muscle layer and was treated by diathermy excision and gold grain implant.

Five patients showed lesions clinically suggestive of carcinoma. A biopsy in one case showed no neoplastic tissue and the remainder were clinically free from tumour a few months later. The cells in the swab sections showed slightly atypical changes, including mitotic figures.

The swabs from the remaining six patients contained cells of regular size and shape and in one case a strip of mucosa 5 or 6 cells thick was also present. One patient with a suspicious lesion developed a clinical recurrence four months later.

\section{DISCUSSION}

Although a small amount of tissue is liable to be lost during processing, almost all of the material removed is available for examination after the swab has dissolved in acetone. The value of the procedure is shown by the large proportion of cases of bladder carcinoma in which it was possible to make an accurate diagnosis.

To determine the criteria of neoplasia in single cells appearances of the swab sections from the control group 1 were compared with those from the neoplastic group 2. Pleomorphic nuclei, well defined nuclear borders, and marked chromatin clumping were found to be distinguishing features. On the other hand, mitotic figures, enlarged nuclei up to $14 \mu$, and prominent nucleoli were present in both groups and are therefore not reliable indicators of neoplasia. When larger aggregates of cells were obtained, some of which contained subepithelial stroma, the cellular pattern was usually similar to that seen in conventional histological material. The transitional cell papilloma, covered by cells similar in appearance to those found in healthy bladder epithelium, cannot be detected by this technique unless papillary fronds are removed.

Apart from those tumours in which the diameter was not recorded, the procedure was performed successfully on lesions of medium size. It may also be possible to apply the technique to small tumours and this may have an important clinical application as their removal for histological diagnosis is technically difficult and there is always some risk of subepithelial implantation (Wallace, 1969).

As transitional cell carcinomas usually present a uniform histological appearance (Pugh, 1958) small fragments are representative. Thus in some patients it has been possible to suggest the histological grading of a carcinoma from examination of fragments in the soluble swab. In the majority of our cases the amount of tissue available for diagnosis was adequate. When carcinoma was present most of the tissue and cells in the section appeared abnormal.

Carcinoma in situ of the bladder may present de novo or, more often, it is a manifestation of recurrent transitional cell carcinoma (Bamforth, 1966). In either case the surgeon is hesitant to biopsy such a lesion and if the examination for exfoliated cells in the urine is unhelpful the patient may present a difficult clinical problem. The solubleswab technique therefore seems ideal for the diagnosis of this condition, and swabbing of the patch of suspicious epithelium may provide the definitive diagnosis, as occurred in one patient from group 3 .

The soluble-swab technique can be used to detect carcinoma of the urethra and we have also obtained samples from the rectum and cervix uteri. In all cases the procedure is atraumatic and material for diagnosis can be removed from a definite area. Processing requires a little more time and technical skill than for an orthodox biopsy and is easily repeated.

The authors wish to thank Mr D. M. Wallace and Dr R. C. B. Pugh for access to material. We are grateful to Mr G. D. Leach for preparing the photomicrographs and to Mrs K. P. Swales for secretarial assistance.

\section{REFERENCES}

Bamforth, J. (1966). Cytological Diagnosis in Medical Practice, p. 190. Churchill, London.

Kuper, S. W. A., Stradling, P., Davis, J., and Shortridge, D. (1966). Lancet, 2, 680.

Pugh, R. C. B. (1958). Postgrad. med.J., 34, 124.

Wallace, D. M. (1969). Personal communication.

Williams, G. (1968). Brit. J. Urol., 40, 703. 